\title{
Regional Climate Change-Science in the Southeast
}

"Management decisions made in response to climate change impacts must be informed by science and require that scientists work in tandem with those managers who are confronting climate change impacts and evaluating options to respond to such impacts."

- Secretary of the Interior Ken Salazar, Secretarial Order 3289 s $3 b$

\section{U.S. Department of the Interior Regional Climate Science Centers}

Resource managers are at the forefront of a new era of management. They must consider the potential impacts of climate change on the Nation's resources and proactively develop strategies for dealing with those impacts on plants, animals, and ecosystems. This requires rigorous, scientific understanding of environmental change.
The role of the U.S. Geological Survey (USGS) in this effort is to analyze climate-change data and develop tools for assessing how changing conditions are likely to impact resources. This information will assist federal, State, local, and tribal partners manage resources strategically. The 2008 Omnibus Budget Act and Secretarial Order 3289 established a new network of eight U.S. Department of the Interior Regional Climate Science Centers to provide technical support for resource managers. The Southeast
Regional Assessment Project (SERAP) is the first regional assessment to be funded by the USGS National Climate Change and Wildlife Science Center (http://nccw.usgs.gov/). The USGS is working closely with the developing U.S. Department of the Interior Landscape Conservation Cooperatives to ensure that the project will meet the needs of resource managers in the Southeast. In addition, the U.S. Fish and Wildlife Service is providing resources to the SERAP to expand the scope of the project.

Flint River, Sprewell Bluff State Park, Upson County, Georgia. Photo by Alan M. Cressler, USGS.
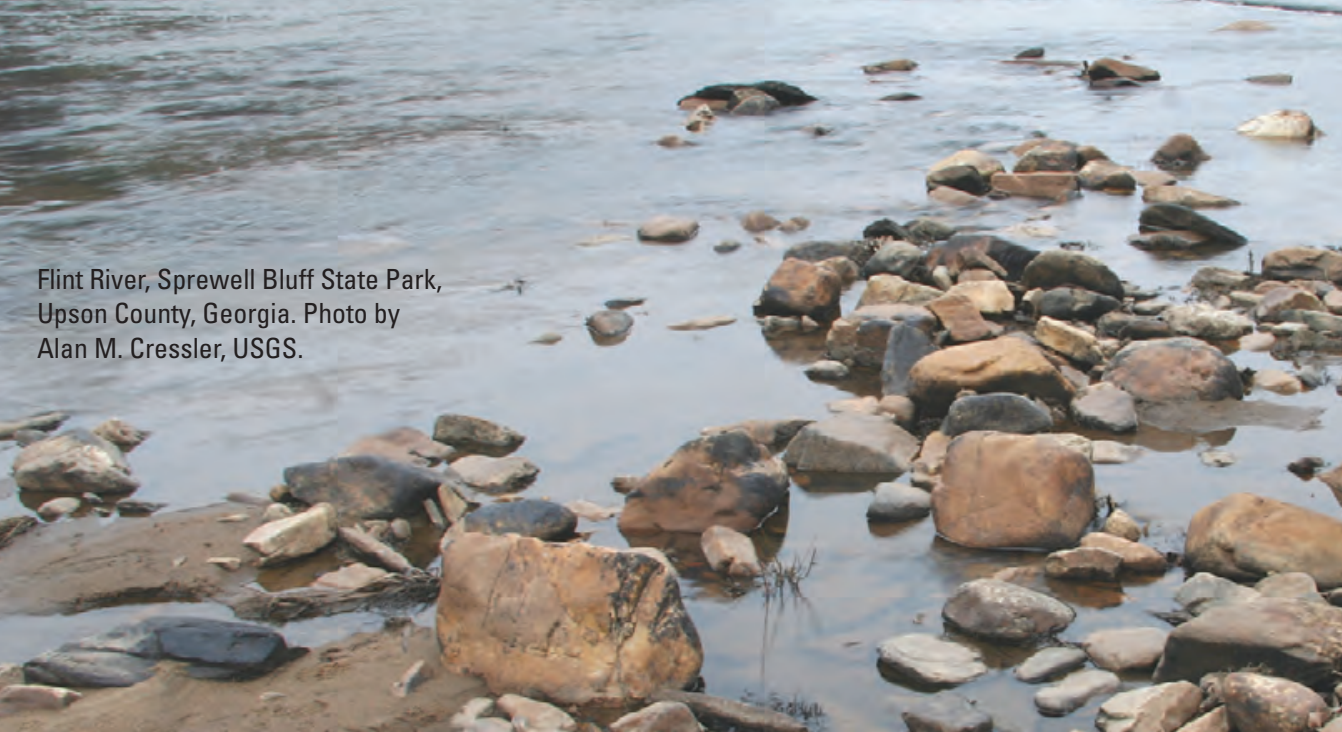


\section{Regional Assessments}

The regional focus of the Climate Science Centers is key to providing science that is useful to resource managers. Regional assessments are a link between the planetary focus of the general circulation models (GCMs) and landscapelevel dynamics that affect local resources. Regional models can analyze the interaction of global changes with local topography and ecosystems. This allows scientists to more precisely pinpoint factors driving change and to determine how these changes affect resources.

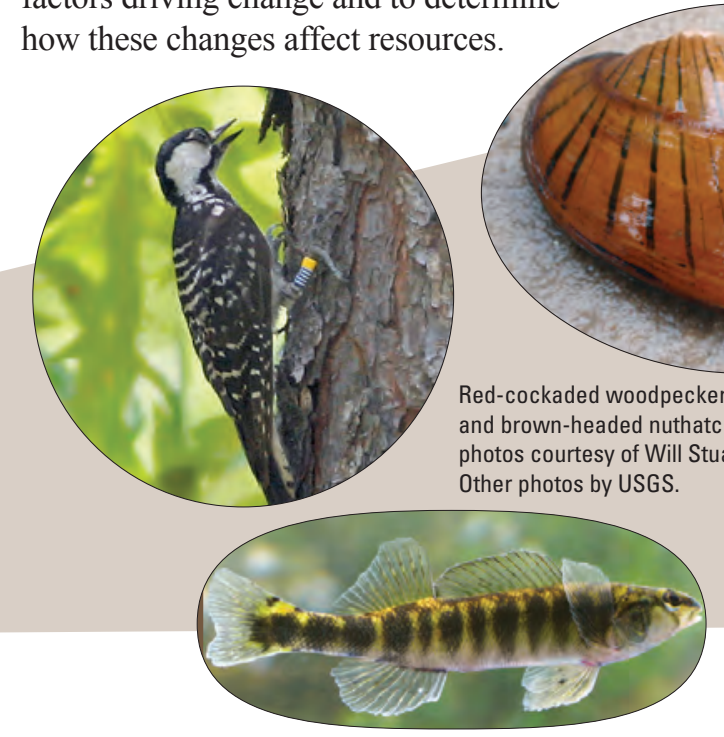

\section{Southeast Regional} Assessment Project

SERAP will convert a suite of global models into regional climate projections and develop landscape change datasets that can be used to project the likely changes to the Southeast's climate and ecosystems. By concurrently downscaling global models while developing changeassessment tools for resource managers, SERAP teams can determine the best approaches for coupling models and effectively provide useful decisionmaking tools for assessing the impacts of climate change.

\section{Downscaling}

The USGS is deploying state-ofthe science statistics to identify the parameters in global models that are most likely to affect the Southeast region's climate and local landscape dynamics. Decision makers will be provided with information about low-probability, highimpact climate extremes. The downscaled models then can be used by other SERAP research teams to conduct their assessments of regional change.

\section{Relative Sea-Level Rise}

To estimate local rates of sea-level rise along the Southeast's Gulf Coast, the USGS is factoring in parameters to represent local processes that affect land-surface elevation and other types of ecosystem changes. The team will design new tools for decision makers to visualize and assess change in coastal regions where a combination of inundation, land loss, and habitat change already is occurring and is expected to continue. in the Apalachicola-ChattahoocheeFlint watershed to improve the ability to detect and project the condition of aquatic habitats. Decision makers will be consulted to determine priority species so that species-specific models can be developed and used to assess the vulnerability of fishes and mussels to climate change.

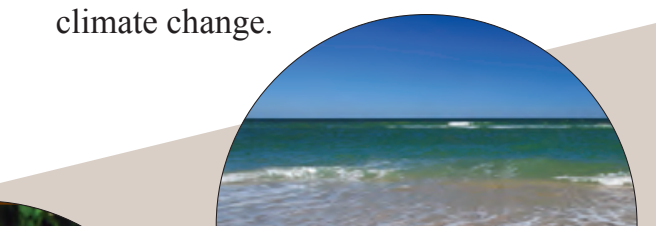

